\title{
Perbandingan Massa Tulang Sebelum dan Sesudah Melakukan Senam Zumba pada Wanita Dewasa
}

\author{
${ }^{1}$ Madeleine N. W. Senduk, ${ }^{2}$ Hedison Polii, ${ }^{2}$ Diana V. D. Doda \\ ${ }^{1}$ Program Studi Pendidikan Dokter Fakultas Kedokteran Universitas Sam Ratulangi Manado \\ ${ }^{2}$ Bagian Fisiologi Fakultas Kedokteran Universitas Sam Ratulangi \\ Email: nadyanolan@gmail.com; vanda.doda@gmail.com
}

\begin{abstract}
Osteopenia commonly occurs in people over 50 years, however, several studies also showed that osteopenia affected young adults. Osteopenia can develop into osteoporosis. International Osteoporosis Foundation estimated that women in Indonesia had risk of developing osteoporosis four times greater than men. Osteopenia and osteoporosis can be prevented by physical exercise such as aerobic exercises inter alia Zumba exercise. This study was aimed to determine whether there was a difference in bone mass before and after 4-week Zumba exercise. This was an experimental study with one group pretest and posttest design conducted on 16 subjects of adult females in a fitness center in Manado, North Sulawesi. Zumba exercise was performed in 4 weeks. Bone mass before and after Zumba exercise was measured by using Bioelectrical Impedance Analysis (BIA). Data were analyzed with paired sample t-test. The results showed that the average of bone mass before Zumba exercise was $2.281 \mathrm{~kg}$ and the average of bone mass after Zumba exercise was $2.306 \mathrm{~kg}$ with a $P$ value of 0.104 . Conclusion: There was no significant difference in bone mass before and after 4 -week Zumba exercise.
\end{abstract}

Keywords: bone mass, Zumba exercise

\begin{abstract}
Abstrak: Osteopenia umumnya terjadi pada orang berusia di atas 50 tahun, namun beberapa penelitian menunjukkan bahwa osteopenia telah menyerang usia muda. Osteopenia dapat berlanjut menjadi osteoporosis. Menurut International Osteoporosis Foundation, risiko osteoporosis pada wanita di Indonesia 4 kali lebih tinggi dibandingkan pria. Osteopenia dan osteoporosis dapat dicegah dengan melakukan aktivitas fisik seperti olahraga aerobik, antara lain senam Zumba. Penelitian ini bertujuan untuk mengetahui apakah terdapat perbedaan massa tulang sebelum dan sesudah melakukan senam Zumba. Jenis penelitian ialah eksperimental lapangan dengan rancangan one group pretest dan posttest yang dilakukan pada 16 wanita dewasa pada salah satu pusat kebugaran di Manado, Sulawesi Utara. Senam Zumba dilaksanakan selama 4 minggu. Massa tulang sebelum dan sesudah senam Zumba diukur menggunakan Bioelectrical Impedance Analysis (BIA). Uji statistik dilakukan menggunakan uji t berpasangan. Hasil penelitian menunjukkan rerata massa tulang sebelum senam Zumba 2,281 $\mathrm{kg}$ dan rerata massa tulang sesudah senam Zumba selama 4 minggu 2,306 $\mathrm{kg}$ dengan nilai $P=0,104$. Simpulan: Tidak terdapat perbedaan bermakna antara massa tulang sebelum dan sesudah melakukan senam Zumba selama 4 minggu.
\end{abstract}

Kata kunci: massa tulang, senam Zumba

Tulang merupakan alat gerak pasif manusia. Selain itu, tulang berperan sebagai alat penunjang tubuh, proteksi alat-alat dalam tubuh, pembentuk tubuh, metabolisme kalsium dan mineral, dan organ hemo- poetik. Tulang yang kuat harus memiliki kepadatan tulang yang baik. Massa tulang yang normal akan mempertahankan kepadatan tulang. ${ }^{1,2}$

Massa tulang dapat mengalami penu- 
runan akibat berbagai macam faktor, contohnya proses penuaan. Seiring peningkatan usia, kecepatan pembentukan tulang akan berkurang secara progresif, dimulai pada usia sekitar 30 atau 40 tahun. Kepadatan tulang yang lebih rendah dari normal dikategorikan sebagai osteopenia dan osteoporosis. ${ }^{1,3,4}$ Hasil penelitian di beberapa kota oleh Pusat Penelitian dan Pengembangan Gizi dan Makanan Depkes RI menunjukkan bahwa osteopenia telah menyerang usia muda di bawah 25 tahun dengan prevalensi $37,1 \%$. Penelitian yang dilakukan oleh Cahyaningsih et $\mathrm{al}^{5}$ tahun 2017 pada 95 mahasiswa berusia 19-25 tahun menunjukkan prevalensi osteopenia sebesar $21,1 \%$ dan prevalensi osteoporosis sebesar $22,1 \%$. Penelitian yang dilakukan pada tahun 2010 di 3 provinsi yaitu Sulawesi Utara, Yogyakarta, dan Jawa Barat menunjukkan risiko osteoporosis sebesar $22,3 \%$ dan osteopenia sebesar $32,7 \%$, dengan proporsi risiko osteoporosis tertinggi terdapat di Sulawesi Utara $(27,7 \%){ }^{5}$

Penurunan massa tulang juga dapat disebabkan oleh faktor lainnya antara lain kurangnya aktivitas fisik. Aktivitas fisik yang kurang akan menghambat aktivitas osteblas sehingga proses pengendapan tulang akan berkurang. ${ }^{6}$ Menurut World Health Organization (WHO) (2018), lebih dari $80 \%$ populasi orang dewasa di seluruh dunia memiliki aktivitas fisik yang kurang. ${ }^{7}$

Aktivitas fisik seperti olahraga yang rutin dapat memengaruhi peningkatan massa tulang dengan menjaga kepadatan dan penurunan kehilangan massa tulang. ${ }^{8}$ Penelitian oleh Alghadir et $\mathrm{al}^{9}$ menunjukkan bahwa latihan aerobik intensitas sedang menghasilkan efek positif yang bermakna terhadap marker pembentuk tulang dan densitas mineral tulang yang dihubungkan dengan pengurangan bermakna dari resorpsi tulang sehingga dapat mencegah terjadinya osteoporosis. Penelitian yang dilakukan oleh Mulidah et al. ${ }^{10}$ menunjukkan bahwa peningkatan massa tulang yang efektif pada wanita postmenopause dapat dicapai dengan melakukan latihan 2 kali seminggu dengan durasi 50 menit.

Salah satu olahraga yang sedang popu- lar saat ini yaitu senam Zumba. Sekitar 14 juta orang dari 150 negara mengikuti senam Zumba. Senam Zumba merupakan gabungan dari musik dan beragam gerakan tarian dengan prinsip aerobik dasar. ${ }^{11,12}$ Penelitian ini bertujuan untuk mengetahui apakah terdapat perbedaan massa tulang sebelum dan sesudah melakukan senam Zumba selama 4 minggu.

\section{METODE PENELITIAN}

Penelitian ini menggunakan metode eksperimental lapangan dengan rancangan one group pretest dan posttest. Penelitian dilaksanakan pada bulan Oktober- November 2018 di salah satu pusat kebugaran di Manado, Sulawesi Utara. Subyek penelitian ialah wanita dewasa yang mengikuti kelas senam Zumba di salah satu pusat kebugaran di Manado, Sulawesi Utara berjumlah 16 orang yang memenuhi kriteria inklusi dan eksklusi. Senam Zumba dilakukan selama 4 minggu dengan frekuensi 3 kali per minggu dan durasi 60 menit. Tahapantahapan dalam senam Zumba meliputi warm up selama 10 menit, bagian inti selama 45 menit, dan cool down selama 5 menit.

Pengukuran massa tulang menggunakan Bioelectrical Impedance Analysis (BIA) jenis Family Dr Body Fat Monitor FEP103. Data diolah menggunakan perangkat lunak dan uji statistik menggunakan uji $\mathrm{t}$ berpasangan.

\section{HASIL PENELITIAN}

Subjek penelitian diwawancarai dan diminta mengisi kuesioner kesiapan aktivitas fisik (PAR-Q) untuk penyaringan. Subjek yang telah memenuhi kriteria inklusi dan eksklusi dimintakan untuk mengisi informed consent.

Karakteristik subjek penelitian berdasarkan usia terbanyak terdapat pada kategori usia 26-35 tahun dan 36-45 tahun masing-masing sebanyak 6 orang $(37,5 \%)$, dan yang paling sedikit terdapat pada kategori usia 18-25 tahun sebanyak 4 orang (25\%) (Tabel 1). Menurut berat badan, subjek penelitian terbanyak terdapat pada kategori berat badan 55-62 kg sebanyak 9 
orang $(56,3 \%)$, dan yang paling sedikit terdapat pada kategori $63-70 \mathrm{~kg}$ sebanyak 1 orang $(6,3 \%)$ (Tabel 2$)$.

Tabel 1. Karakteristik subjek berdasarkan usia

\begin{tabular}{ccc}
\hline $\begin{array}{c}\text { Usia } \\
\text { (tahun) }\end{array}$ & $\begin{array}{c}\text { Frekuensi } \\
(\mathbf{n})\end{array}$ & $\begin{array}{c}\text { Persentase } \\
(\boldsymbol{\%})\end{array}$ \\
\hline $18-25$ & 4 & 25 \\
$26-35$ & 6 & 37,5 \\
$36-45$ & 6 & 37,5 \\
Total & 16 & 100 \\
\hline
\end{tabular}

Tabel 2. Karakteristik subjek berdasarkan berat badan

\begin{tabular}{ccc}
\hline $\begin{array}{c}\text { Berat badan } \\
(\mathbf{k g})\end{array}$ & $\begin{array}{c}\text { Frekuensi } \\
(\mathbf{n})\end{array}$ & $\begin{array}{c}\text { Persentase } \\
(\mathbf{\%})\end{array}$ \\
\hline $47-54$ & 3 & 18,8 \\
$55-62$ & 9 & 56,3 \\
$63-70$ & 1 & 6,3 \\
$>70$ & 3 & 18,8 \\
Total & 16 & 100 \\
\hline
\end{tabular}

Berdasarkan tinggi badan, subjek penelitian terbanyak terdapat pada kategori tinggi badan $>155 \mathrm{~cm}$ sebanyak 10 orang $(62,5 \%)$ (Tabel 3).

Berdasarkan indeks massa tubuh (IMT), subjek penelitian terbanyak terdapat pada kategori IMT $\geq 25$ (obesitas) sebanyak 7 orang $(43,8 \%)$ dengan rerata massa tulang sebesar $2,500 \mathrm{~kg}$, dan yang paling sedikit terdapat pada kategori IMT 23,024,9 (pre-obes) sebanyak 4 orang $(25,0 \%)$ dengan rerata massa tulang sebesar 2,175 $\mathrm{kg}$ (Tabel 4).

Tabel 3. Karakteristik subjek berdasarkan tinggi badan

\begin{tabular}{ccc}
\hline $\begin{array}{c}\text { Tinggi badan } \\
(\mathbf{c m})\end{array}$ & $\begin{array}{c}\text { Frekuensi } \\
(\mathbf{n})\end{array}$ & $\begin{array}{c}\text { Persentase } \\
(\mathbf{\%})\end{array}$ \\
\hline $147-155$ & 6 & 37,5 \\
$>155$ & 10 & 62,5 \\
Total & 16 & 100 \\
\hline
\end{tabular}

Tabel 4. Karakteristik subjek berdasarkan IMT

\begin{tabular}{cccc}
\hline IMT & $\begin{array}{c}\text { Frekuensi } \\
(\mathbf{n})\end{array}$ & $\begin{array}{c}\text { Persentase } \\
(\mathbf{\%})\end{array}$ & $\begin{array}{c}\text { Rerata massa } \\
\text { tulang }(\mathbf{k g})\end{array}$ \\
\hline $18,5-22,9$ (normal) & 5 & 31,3 & 2,060 \\
$23,0-24,9$ (pre-obes) & 4 & 25,0 & 2,175 \\
$\geq 25$ (obesitas) & 7 & 43,8 & 2,500 \\
Total & 16 & 100 & \\
\hline
\end{tabular}

\section{Hasil Pengukuran Massa Tulang}

Rerata massa tulang subjek sebelum senam Zumba yaitu 2,281 kg dengan nilai nilai minimum $1,5 \mathrm{~kg}$, nilai maksimum 2,9 $\mathrm{kg}$, dan standar deviasi 0,3487. Rerata massa tulang sesudah senam Zumba yaitu 2,306 $\mathrm{kg}$ dengan nilai minimum $1,7 \mathrm{~kg}$, nilai maksimum $2,9 \mathrm{~kg}$, dan standar deviasi 0,3172 (Tabel 5).

Sebaran data diuji menggunakan uji Saphiro-Wilk. Karena data terdistribusi normal maka dilanjutkan dengan analisis menggunakan uji t berpasangan dan didapatkan nilai $P=0,104(P>0,05)$ yang berarti tidak terdapat perbedaan bermakna antara massa tulang sebelum dan sesudah senam Zumba.
Tabel 5. Massa tulang subjek sebelum dan sesudah senam Zumba

\begin{tabular}{ccc}
\hline Klasifikasi & \multicolumn{2}{c}{ Massa tulang (kg) } \\
& Sebelum & Sesudah \\
\hline Rerata & 2,281 & 2,306 \\
Std. Deviasi & 0,3487 & 0,3172 \\
Nilai minimum & 1,5 & 1,7 \\
Nilai maksimum & 2,9 & 2,9 \\
\hline
\end{tabular}

\section{BAHASAN}

Berdasarkan hasil penelitian, didapatkan $P=0,104(P>0,05)$ yang mmenunjukkan tidak terdapat perbedaan massa tulang sebelum dan sesudah melakukan senam Zumba. Hasil pengukuran massa tulang pada subjek penelitian setelah melakukan 
senam Zumba selama 4 minggu dengan frekuensi 3 kali per minggu dan durasi 60 menit menunjukkan adanya peningkatan namun tidak bermakna.

Beberapa penelitian menjelaskan bahwa aktivitas fisik merupakan salah satu faktor yang dapat meningkatkan massa tulang. Aktivitas fisik seperti olahraga akan memberikan stres dan tekanan terhadap tulang, akibatnya kecepatan pengendapan tulang akan semakin meningkat, sehingga terjadilah peningkatan massa tulang. ${ }^{1}$ Menurut studi dari American College of Sports Medicine (ACSM), senam Zumba yang dilakukan secara rutin dapat memberikan dampak positif terhadap komposisi tubuh. $^{13}$

Penelitian yang dilakukan oleh Alev di Turki menunjukkan adanya penurunan resorpsi tulang pada kelompok wanita premenopause yang diberikan latihan aerobik. ${ }^{14}$ Penelitian oleh Sokhanvardastjerdi et al $^{15}$ di Iran terhadap 45 wanita berusia 38 43 tahun menunjukkan adanya peningkatan densitas mineral tulang setelah melakukan latihan aerobik selama 3 bulan. Studi dari Marks ${ }^{16}$ mendapatkan bahwa latihan aerobik seperti berlari dapat meningkatkan densitas mineral tulang pada wanita usia muda.

Penelitian lain melaporkan hasil berbeda yaitu tidak adanya efek latihan fisik terhadap massa tulang. Studi dari Gregov dan Salaj ${ }^{17}$ mendapatkan bahwa latihan aeorbik pada wanita dewasa sampai pasca menopause tidak dapat meningkatkan massa tulang tetapi dapat mempertahankan dan/atau mengurangi kehilangan massa tulang. Utami dan Indraswari ${ }^{18}$ meneliti wanita berusia 20-22 tahun yang dibagi menjadi 2 kelompok yaitu kelompok yang melakukan latihan aerobik dan kelompok yang melakukan latihan aerobik ditambah latihan otot; masing-masing kelompok terdiri dari 13 orang. Latihan ini diberikan selama 8 minggu dengan frekuensi 2 kali seminggu. Hasil penelitiannya menunjukkan tidak terdapat perbedaan bermakna massa tulang, baik pada kelompok yang melakukan latihan aerobik maupun kelompok yang melakukan latihan aerobik beserta latihan otot. Ljubojevic et al. ${ }^{19}$ menyatakan bahwa pada 12 wanita berusia 25-35 tahun yang melakukan senam Zumba selama 8 minggu tidak terdapat peningkatan bermakna dari massa bebas lemak tubuh walaupun terdapat adanya sedikit peningkatan. Massa bebas lemak tubuh meliputi massa otot, massa tulang, serta jaringan-jaringan tubuh lainnya yang bebas lemak. $^{19}$

Studi dari Gaudalupe-Grau A et al. ${ }^{20}$ menunjukkan bahwa jenis metode latihan untuk meningkatkan massa tulang masih belum jelas. Latihan aerobik dan weightbearing penting untuk mempertahankan kesehatan tulang, tetapi latihan resistensi menunjukkan efek yang lebih besar terhadap kepadatan tulang. Marques et al. ${ }^{21}$ melakukan penelitian terhadap 71 wanita lanjut usia yang dibagi menjadi 3 kelompok, yaitu: kelompok yang melakukan latihan aerobik, latihan resistensi, dan kelompok kontrol. Latihan ini dilakukan selama 8 bulan dengan frekuensi 3 kali per minggu. Hasil penelitian tersebut menunjukkan bahwa latihan resistensi meningkatkan densitas mineral tulang, kekuatan otot, serta keseimbangan, sedangkan latihan aerobik tidak meningkatkan densitas mineral tulang, tetapi meningkatkan keseimbangan. ${ }^{21}$ Penelitian-penelitian ini menunjukkan bahwa latihan anaerobik lebih efektif terhadap densitas mineral tulang dari pada latihan aerobik karena latihan anerobik dapat memberikan tekanan yang lebih besar terhadap tulang sehingga memberikan efek ostegenik yang lebih besar dan dapat memicu osteogenesis, sehingga dapat meningkatkan kepadatan tulang. ${ }^{20,21}$

Hasil penelitian ini menunjukkan tidak terdapat perbedaan bermakna massa tulang sebelum dan sesudah melakukan senam Zumba. Berdasarkan data pengukuran, didapatkan 3 subjek yang mengalami peningkatan massa tulang. Ketiga subjek ini memiliki massa tulang di bawah nilai estimasi menurut Tanita Institue, sedangkan subjek penelitian lainnya sebagian besar memiliki massa tulang yang sesuai dengan nilai estimasi. Hal ini diduga yang menyebabkan tidak terjadinya penambahan 
massa tulang pada sebagian besar subjek, namun tidak ditemukan juga adanya penurunan massa tulang.

Perbedaan berbagai hasil penelitian yang telah dikemukakan di atas juga dapat dipengaruhi oleh beberapa faktor seperti usia, berat badan, tinggi badan, pekerjaan, asupan gizi, durasi latihan fisik, serta alat ukur yang digunakan. Peneliti tidak meninjau beberapa faktor tersebut. Selain itu, jumlah subjek penelitian juga terbatas dan waktu penelitian ini hanya dapat dilaksanakan selama 4 minggu yang dapat memengaruhi hasil penelitian.

\section{SIMPULAN}

Berdasarkan hasil penelitian ini dapat disimpulkan bahwa tidak terdapat perbedaan bermakna antara massa tulang sebelum dan sesudah melakukan senam Zumba.

\section{SARAN}

Perlu dilakukan penelitian lanjut dengan jumlah subjek yang lebih besar dan cakupan yang lebih luas serta waktu dan frekuensi yang lebih lama.

Dapat dilakukan pengukuran yang lebih spesifik terhadap densitas mineral tulang menggunakan Dual Energy X-Ray Absorpsiometry (DXA) atau Quantitative Ultrasound untuk dapat mengidentifikasi kepadatan tulang seseorang apakah normal, osteopenia, atau osteoporosis.

\section{DAFTAR PUSTAKA}

1. Sherwood L. Fisiologi Manusia dari Sel ke Sistem (6th ed). Jakarta: ECG, 2012.

2. Setiyohadi B. Struktur dan Metabolisme Tulang. In: Setiati S, Alwi I, Sudoyo AW, Simadibrata M, Setiyohadi B, Syam AF. Buku Ajar Ilmu Penyakit Dalam (6th ed). Jakarta: Interna Publilshing, 2014; p. 3423-9.

3. Andriani R. Faktor-faktor yang berhubungan dengan kepadatan tulang pada lansia awal di Puskesmas Pisangan Tangerang Selatan Tahun 2016 [Skripsi]. Jakarta: Universitas Islam Negeri Syarif Hidayatullah; 2016.

4. Hirsch JA. Osteopenia and osteoporosis: Is there a difference? 2014. [cited 2018 Oct 8]. Available from: http://www. spineuniverse.com/conditions/ osteoporosis/osteopenia-osteoporosisthere-difference

5. Cahyaningsih MN, Saraswati LD, Yuliawati S, Wuryanto MA. Gambaran densitas mineral tulang (DMT) pada kelompok dewasa awal (19-25 tahun) (studi di Fakultas Kesehatan Masyarakat Universitas Diponegoro). Jurnal Kesehatan Masyarakat. 2017;5(4):424-30.

6. Kementrian Kesehatan Republik Indonesia. Infodatin data kondisi penyakit osteoporosis di Indonesia. Jakarta: Pusat Data dan Informasi Kementrian Kesehatan RI, 2015.

7. World Health Organization. Physical activity. 2018. [cited 2018 Sept 1]. Available from: http://www.who.int/news-room/ fact-sheets/detail/physical-activity

8. NIH Osteoporosis and Related Bone Diseases. Osteoporosis: Peak Bone Mass in Women. [cited 2018 Sept 18]. Available from: https://www.bones.nih. gov/health-info/bone/osteoporosis/ bone-mass

9. Alghadir AH, Aly FA, Gabr SA. Effect of moderate aerobic training on bone metabolism indices among adult humans. Pak J Med Sci. 2014;30(4): 840-4.

10. Mulidah S, Asrin, Haryati W, Sulistyowati DID. Efektivitas frekuensi latihan dalam meningkatkan kepadatan massa tulang pada wanita menopause. Jurnal Unimus. 2012. Available from: jurnal. unimus.ac.id/index.php/psn12012010/ article/viewFile/1289/1342.

11. Inouye J, Nichols A, Tseng CW. A survey of musculoskeletal injuries associated with Zumba. Hawaii J Med Public Health. 2013;72(12):433-6.

12. Sukma AT. Efek Zumba terhadap penurunan tebal lemak bawah kulit dan berat badan Member DF Fitness dan Aerobic [Skripsi]. Yogyakarta: Universitas Negeri Yogyakarta; 2016.

13. Luettgen M, Foster C, Doberstein S, Mikat R, Porcari J. Zumba ${ }^{\circledR}$ : Is the "fitnessparty" a good workout? J Sports Sci Med. 2012;11(2):357-8.

14. Alev ALP. Effects of Aerobic exercise on bone-specific alkaline phosphatase and urinary CTX levels in premenopausal women. Turk J Ph Med Rehab. 2013; 59:310-3. 
22 Jurnal Biomedik (JBM), Volume 11, Nomor 1, Maret 2019, hlm. 17-22

15. Sokhanvardastjerdi S, Golami M, Hafezi $\mathbf{F}$, Khanzadeh N. Effects of aerobic exercise on SHBG, bone density in overweight middle-aged women. Eur J Exp Bio. 2014;4(1):642-5.

16. Marks R. Aerobic exercise for preventing osteoporosis in postmenopausal women: an update of its effect on bone mineral density. Curr Rheumatol Rev. 2012;8(2):141-59.

17. Gregov C, Salaj S. The effects of different training modalities on bone mass: a review. Kinesiology: International Kinesiol Int J Fundam Appl Kinesiol. 2014;46(Suppl 1): 10-29.

18. Utami WP, Indraswari DA. Perbandingan pengaruh lari rutin dengan lari rutin ditambah latihan otot inti terhadap persentase lemak dan massa tulang pada mahasiswi Fakultas Kedokteran UNDIP. Jurnal Kedokteran Diponegoro. 2016;5(4):1886-93.

19. Ljubojevic A, Jakovljevic V, Poprzen M. Effects of Zumba fitness program on body composition of women. SportLogia. 2014;10(1):29-33.

20. Gaudalupe-Grau A, Fuentes T, Guerra B, Calbet JAL. Exercise and bone mass in adults. Sports Med. 2009;39(6):43968.

21. Marques EA, Wanderley F, Machado L, Susa F, Viana JL, MoreiraGoncalves D, et al. Effects of resistance and aerobic exercise on physical function, bone mineral density, OPG and RANKL in older women. Exp Gerontol. 2011;46(7):524-32. 